\title{
A phase lb study of pembrolizumab plus chemotherapy in patients with advanced cancer (PembroPlus)
}

\author{
Glen J Weiss ${ }^{*}{ }^{1}$, Jordan Waypa ${ }^{1}$, Lisa Blaydorn ${ }^{1}$, Jessica Coats ${ }^{1}$, Kayla McGahey $^{1}$, Ashish Sangal ${ }^{1}$, Jiaxin Niu ${ }^{1}$, \\ Cynthia A Lynch ${ }^{1}$, John H Farley ${ }^{1}$ and Vivek Khemka ${ }^{1}$ \\ ${ }^{1}$ Western Regional Medical Center, Cancer Treatment Centers of America, 14200 W Celebrate Life Way, Goodyear, AZ 85338, USA
}

Background: Pembrolizumab (P) is an anti-PD-1 antibody that blocks the interaction between programmed cell death protein 1 (PD-1) on T-cells and PD-L1 and PD-L2 on tumour cells. A phase lb trial of P plus chemotherapy was undertaken to evaluate the safety and efficacy.

Methods: Patients with advanced, metastatic solid tumours were enrolled onto one of six treatment arms. Pembrolizumab was given: with gemcitabine (G), G + docetaxel (D), G + nab-paclitaxel (NP), G + vinorelbine (V) or irinotecan (I) until progression or toxicity, or with liposomal doxorubicin (LD) for up to 15 cycles, progression or toxicity. Safety monitoring and response assessments were conducted.

Results: Forty-nine patients were enrolled and treated. The most common adverse events were transaminitis, cytopenias, rash, diarrhoea, fatigue, nausea and vomiting. Arm 2 was closed due to poor accrual. The recommended phase II dose (RP2D) was determined for Arms 1, 3a, 4, 5 and 6. There were eight partial responses across multiple tumour types.

Conclusions: Standard dose P can be safely combined with G, G+NP, G+V, I and LD. Efficacy was observed in multiple tumour types and evaluation to determine if response and duration of response are more robust than what would be expected for chemotherapy or immunotherapy alone requires further validation.

In recent years, there has been fervor over the potential promise of immunotherapy for treating advanced solid tumours. Interest was piqued by the first reports of single agent activity of checkpoint inhibitors in low immunogenic cancers such as non-small cell lung cancer (NSCLC) (Herzberg et al, 2016). Since 2014, there are now three FDA approved inhibitors of programmed cell death protein 1 (PD-1) and PD-1 ligand (PD-L1) with indications across a number of solid tumours, including NSCLC. Yet, for many patients with advanced cancers under those approved indications and many more patients with other types of tumours, the responses and durability of those responses have significant room for improvement.

Cancers may possess multiple modalities to evade immune response including secreting cytokines such as TGF- $\beta$ and IL-10 or other molecules such as PD-L1 and forming an immune suppressive microenvironment populated with T-regulatory cells (Tregs), macrophages and myeloid-derived suppressor cells (MDSCs) (Duffy and Greten, 2014). By causing apoptotic cell death of cancer cells, chemotherapy can be immunogenic by stimulating anticancer immune effectors directly or mitigating immunosuppressive mechanisms (Zitvogel et al, 2011). Systemic chemotherapy may stimulate immunosurveillance by antigenicity, immunogenicity or susceptibility (Zitvogel et al, 2013). Antigenicity is the result of increasing the expression or presentation of tumour-associated antigens on the cell surface of cancer cells. Immunogenicity is causing tumour cells to emit 'danger' signals that trigger innate immune responses by operating as adjuvants.

*Correspondence: Dr GJ Weiss; E-mail: drglenweiss@outlook.com

Received 6 January 2017; revised 25 April 2017; accepted 26 April 2017; published online 6 June 2017

(C) 2017 Cancer Research UK. All rights reserved 0007-0920/17 
Susceptibility is enhancing the likelihood that tumour cells will be recognised and killed by immune effectors.

One means to improve on the efficacy of this approach potentially involves the combination of checkpoint inhibition with agents or tools of different mechanisms of action in the hopes of a deliverance of a windfall of synergism (e.g., chemotherapy, radiotherapy, targeted therapy or other types of immunotherapy). There have been recent clinical data on synergetic effects of cytotoxic chemotherapy given in combination with checkpoint inhibitors (Langer et al, 2016; Rizvi et al, 2016). We hypothesise that with sufficient tumour cell kill with the combination of systemic cytotoxic and pembrolizumab (P), a PD-1 inhibitor, the response may be enhanced to achieve long durable complete responses. This phase Ib study was designed to identify the recommended phase II dose (RP2D) for several systemic chemotherapies in combination with $\mathrm{P}$.

\section{MATERIALS AND METHODS}

Study design. This Phase Ib, open-label trial included six separate treatment arms for adults with advanced solid tumours and was performed at a single centre in the United States. Enrolment on the phase Ib portion was between 19 December 2014 and 22 July 2015. Prior to initiating any protocol-related activities, signed written informed consent was obtained from each patient. The study protocol, amendments to the protocol and the sample informed consent file were reviewed and approved by the Western Institutional Review Board (WIRB) and the study was registered on clinicaltrials.gov (NCT02331251). The study conformed to Good Clinical Practice guidelines and in accordance with the ethical principles set forth in the Declaration of Helsinki.

P $2 \mathrm{mg} \mathrm{kg}^{-1}$ was administered intravenously over $30 \mathrm{~min}$ every 21 days and infused prior to the start of the assigned chemotherapy arm. No dose reductions of $\mathrm{P}$ were permitted. The starting dose levels for each treatment arm were as follows:

- Arm 1: Gemcitabine $1000 \mathrm{mg} \mathrm{m}^{-2}$ on day 1 and day 8 every 21 days.

- Arm 2: Gemcitabine $900 \mathrm{mg} \mathrm{m}^{-2}$ on day 1 and day 8 and docetaxel $75 \mathrm{mg} \mathrm{m}^{-2}$ on day 8 every 21 days.

- Arm 3: Gemcitabine $1000 \mathrm{mg} \mathrm{m}^{-2}$ and nab-paclitaxel $125 \mathrm{mg} \mathrm{m}^{-2}$ on day 1 and day 8 every 21 days.

- Arm 4: Gemcitabine $1000 \mathrm{mg} \mathrm{m}^{-2}$ and vinorelbine $25 \mathrm{mg} \mathrm{m}^{-2}$ on day 1 and day 8 every 21 days.

- Arm 5: Irinotecan $300 \mathrm{mg} \mathrm{m}^{-2}$ on day 1 every 21 days.

- Arm 6: Liposomal doxorubicin $30 \mathrm{mg} \mathrm{m}^{-2}$ on day 1 every 21 days (note: the total cumulative dose of liposomal doxorubicin allowed on this protocol is $450 \mathrm{mg} \mathrm{m}^{-2}$ or 15 cycles if there are no dose reductions).

Criteria for inclusion in and exclusion from the study are listed in Section 1 of the Supplementary Section. Patients remained on treatment until disease progression (PD), refusal, withdrawal of consent or occurrence of unacceptable toxicity.

Study end points. The primary objective of the study was to determine the RP2D of chemotherapy in combination with $\mathrm{P}$ in subjects with advanced cancer. Secondary objectives included determining (i) the frequency of grade 3 or higher treatment-related adverse events, (ii) the response rate by immune-related response criteria (irRECIST) (Nishino et al, 2013) and response evaluation criteria in solid tumours (RECIST) 1.1 criteria (Eisenhauer et al, 2009) and (iii) the overall survival and progression-free survival for enrolled patients.

Assignment of study participants to treatment groups and dose de-escalation modalities. The dose de-escalation scheme
(Le Tourneau et al, 2009) was initiated whereby standard doses for cytotoxic chemotherapy were based or modified to conform with an every 21-day dosing cycle to coincide with standard P dosing at the time of study launch. For example, Arm 3 omitted day 15 gemcitabine and nab-paclitaxel dosing, and on Arm 6 liposomal doxorubicin was based on routine medical oncology practice dosing of $40 \mathrm{mg} \mathrm{m}^{-2}$ on a 28-day schedule and converted to $30 \mathrm{mg} \mathrm{m}^{-2}$ on a 21 -day schedule. If on any of the treatment arms, $\leqslant 1$ of 3 patients experienced first cycle DLT, up to 3 more patients were enrolled. If $\geqslant 2$ or more patients on a dose level experienced first cycle DLTs, the MTD was considered to have been exceeded and 3 patients were treated at the predefined lower dose level. To be declared the RP2D, the dose level being explored would require no more than one of six patients with a DLT.

Toxicity was graded according to the NCI CTCAE version 4.03, with DLT being defined in this study as any event for which the relationship to study treatment could not be definitely excluded. Events that can classify a DLT are provided in Section 2 of the Supplementary Section.

Subjects were replaced if they do not complete the planned dose on cycle 1 day 1 because of an infusion reaction, provided that the infusion reaction was not grade 3 or higher.

Treatment. No more than two intrapatient dose de-escalations were allowed. Initially, dexamethasone premedication was not allowed. However, upon observation of increased nausea, vomiting (despite use of other antiemetic agents), as well as rash and oedema in the extremities due to the systemic chemotherapy, the protocol was amended in September 2015 to require dexamethasone $12 \mathrm{mg}$ intravenous premedication on the days of systemic chemotherapy administration. This decision was also based on observations that safety and efficacy from other ongoing immunotherapy plus chemotherapy trials at the time were not impeded by steroid premedication. Recommended dose modifications in Supplementary Table S1 were only applied to toxicities observed during or after the first and subsequent cycles of treatment.

Removal of participants from treatment or assessment. Patients could continue therapy unless there was PD at any time, they experienced unacceptable toxicity dictating cessation of treatment, there was a change in their medical status (including pregnancy) such that the investigator believed that their safety was compromised or that it was in their best interest to stop treatment, they withdrew consent, they were non-compliant with protocol requirements or were lost to follow-up.

Efficacy assessments. Determination of antitumour efficacy was based on objective tumour assessments performed according to RECIST 1.1 (Eisenhauer et al, 2009) and irRECIST (Nishino et al, 2013), and treatment decisions by the investigator were based on these assessments. A clinically stable patient meeting criteria for PD on RECIST 1.1 but with stable disease (SD) or better by irRECIST was permitted to continue on protocol until there was clinical deterioration, significant toxicity or PD by irRECIST.

Safety assessments. Severity of AEs was graded according to NCI CTCAE version 4.03 . For each event, the highest severity grade attained was reported. The causality between each AE and study treatment was classified according to the following terms: definitely not related, unlikely related, likely related and definitely related.

Statistical and analytical plans. For the evaluation of the primary end point (i.e., RP2D), all treated patients were considered, except those who had failed to receive a complete first cycle of treatment for reasons other than DLTs. In this case, these patients were replaced with additional patients at the same dose level, in accordance with the protocol. All patients who were evaluable for the primary end point were displayed in the study outputs. 


\section{RESULTS}

A total of 50 patients were enrolled and 49 patients were dosed on the Phase Ib study. One patient was enrolled but never treated due to an acute GI bleed prior to initiation of treatment. Two patients were unevaluable for DLT assessment and were replaced. At the time of data-cutoff on 1 December 2016, all patients were off study treatment.

The median age at study entry was 55 years and 36 were women (Tables 1 and 2). All but one patient had a KPS performance status of $80 \%$ or better at the time of enrolment. The most common cancer types included breast cancer (12 patients), pancreatic adenocarcinoma (PDAC) (11 patients), NSCLC (8 patients), sarcoma (7 patients), small cell lung cancer (SCLC) (5 patients) and ovarian cancer ( 2 patients). At study entry, all patients were pathologically confirmed to have advanced metastatic disease. Thirty-seven patients (75.6\%) including all patients in arms 1, 2, 4 and 5 had been pretreated (having received at least one prior systemic therapy (e.g., chemotherapy, targeted therapy or hormonal therapy) that had been used mostly in the metastatic setting). The number of treatment cycles per patient per treatment arm is provided in Supplementary Table S2.

Dose de-escalation by arm and first cycle DLTs. In Arm 1, there was one DLT (received less than 25\% planned dose due to grade 4 neutropenia), and RP2D is gemcitabine $1000 \mathrm{mg} \mathrm{m}^{-2}$ days 1 and 8 every 21 days with $\mathrm{P}$ on day 1 . Arm 2 enrolled one patient and was closed for futility after observing that several prescreened patients would not be eligible for this treatment arm and it would not accrue in an adequate time frame. Arm 3 initially enrolled treatment naïve and previously treated PDAC patients. There were two DLTs (grade 3 thrombocytopenia) observed in the first five

Table 1. Demographic, baseline and other patient characteristics

\begin{tabular}{|c|c|c|}
\hline & \multicolumn{2}{|c|}{ Treated patients $(N=49)$} \\
\hline Variable & $n$ & $\%$ \\
\hline \multicolumn{3}{|l|}{ Demographic characteristics } \\
\hline \multicolumn{3}{|l|}{ Age (years) } \\
\hline Median (range) & & $55(27-74)$ \\
\hline \multicolumn{3}{|l|}{ Sex } \\
\hline Male & 13 & 26.5 \\
\hline Female & 36 & 73.5 \\
\hline \multicolumn{3}{|l|}{ Performance status (KPS) } \\
\hline 100 & 2 & 4.1 \\
\hline 90 & 19 & 37.8 \\
\hline 80 & 27 & 55.1 \\
\hline 70 & 1 & 2 \\
\hline \multicolumn{3}{|l|}{ Disease characteristics } \\
\hline \multicolumn{3}{|l|}{ Primary diagnosis } \\
\hline Breast cancer & 12 & 24.5 \\
\hline Pancreatic cancer & 11 & 22.4 \\
\hline NSCLC & 8 & 16.3 \\
\hline Sarcoma & 7 & 14.3 \\
\hline SCLC & 5 & 10.2 \\
\hline Ovarian cancer & 2 & 4.1 \\
\hline Other & 3 & 6.1 \\
\hline \multicolumn{3}{|c|}{ Prior anticancer therapies for metastatic disease } \\
\hline \multicolumn{3}{|l|}{ Type of prior therapies, } \\
\hline Systemic only & 19 & 38.8 \\
\hline Surgery + Systemic & 2 & 4.1 \\
\hline Systemic + Radiotherapy & 16 & 32.7 \\
\hline Surgery + Systemic + Radiotherapy & 1 & 2 \\
\hline \multicolumn{3}{|c|}{ 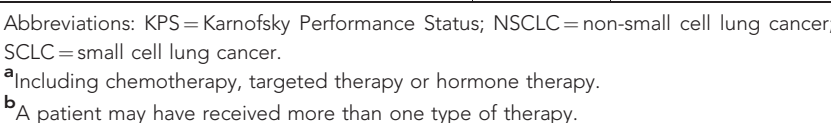 } \\
\hline
\end{tabular}

patients. Upon further review, these DLTs were seen only in previously treated PDAC patients. The protocol was amended to split this arm into $3 \mathrm{a}$ (treatment naïve PDAC) and $3 \mathrm{~b}$ (previously treated PDAC), where Arm $3 \mathrm{~b}$ was dose reduced to gemcitabine $800 \mathrm{mg} \mathrm{m}^{-2}$ and nab-paclitaxel $100 \mathrm{mg} \mathrm{m}^{-2}$ on days 1 and 8 every 21 days with $\mathrm{P}$ on day 1 . The RP2D for Arm 3a is gemcitabine $1000 \mathrm{mg} \mathrm{m}^{-2}$ and nab-paclitaxel $125 \mathrm{mg} \mathrm{m}^{-2}$ on days 1 and 8 every 21 days with $\mathrm{P}$ on day 1 . On dose level 1 on Arm 4, there were two DLTs in six patients (received less than $25 \%$ planned dose due to grade 3 and grade 4 neutropenia, respectively). On dose level -1, there was one DLT in six patients (grade 3 thrombocytopenia) and the RP2D for Arm 4 is gemcitabine $800 \mathrm{mg} \mathrm{m}^{-2}$ and vinorelbine $20 \mathrm{mg} \mathrm{m}^{-2}$ on days 1 and 8 every 21 days with $\mathrm{P}$ on day 1 . On dose level 1 on Arm 5 there were two DLTs in five patients (grade 3 fatigue and grade 3 nausea, vomiting, and diarrhoea). On dose level -1 , one patient withdrew consent and was not evaluable for DLT. At this dose level, there was one DLT in six patients (grade 3 rash and papilloedema), and the RP2D for Arm 5 is irinotecan $250 \mathrm{mg} \mathrm{m}^{-2}$ with $\mathrm{P}$ on day 1 every 21 days. Arm 6 had one patient that developed a grade 2 infusion reaction within the first $2 \mathrm{~min}$ of liposomal doxorubicin infusion and because of safety concerns with drug re-challenging, she was removed from the study and replaced. Going forward, premedication with diphenhydramine was mandatory on Arm 6 and there were no DLTs in the subsequent six patients. The RP2D for Arm 6 is liposomal doxorubicin $30 \mathrm{mg} \mathrm{m}^{-2}$ with P on day 1 every 21 days (Table 3 ).

Safety results by treatment arm. All (100\%) receiving study treatment experienced at least one treatment-emergent $\mathrm{AE}$ (TEAE), with 28 patients $(57.1 \%)$ experiencing TEAEs of grade 3-4 (Table 4). Once dexamethasone premedication was introduced to all subsequent patients (affecting Arms 3-5), the incidence of gastrointestinal AEs (e.g., nausea, vomiting) and oedema in the extremities and rash decreased.

Immune-related adverse events (irAEs) (likely or definitely related) were reported in 50\%, 100\%, 77.8\%, $0 \%, 33.3 \%, 33.3 \%$ and $57.1 \%$ of patients on Arms 1, 2, 3a, 3b, 4, 5 and 6, respectively. Of these, two irAEs led to a dose reduction (both DLTs, one in Arm 4 for grade 3 hypoxia with grade 2 nausea and vomiting and the other in Arm 5 for grade 3 rash and papilloedema). Patient level TEAEs are provided in Supplementary Table S2.

After mandatory premedication with dexamethasone was initiated (see Supplementary Table S2), the frequency of grade $3 / 4$ events appears to have decreased. The average number of grade $3 / 4$ events per patient that enrolled prior to this amendment was 1.1 vs 0.75 grade $3 / 4$ events per patient, respectively. The incidence of likely or definitely related irAEs for patients was also higher prior to the amendment at 20 of 37 (54.1\%) compared with 4 of 12 $(33.3 \%)$.

Two patients died during the study (i.e., within 30 days of coming off study) due to PD (one case each of PDAC and NSCLC, respectively), but these deaths were deemed not to be related to the study medication.

Efficacy results by treatment arm. Forty-five of 49 patients (92\%) treated on the study were evaluable for efficacy. On Arm 1, the best response was PD. On Arm 2, the best response was SD. On Arm $3 a$, the best response was partial response (PR) for two patients and SD for six patients. On Arm 3b, the best response was PD. On Arm 4, the best response was PR for one patient, SD for three patients, and PD for 7 patients. On Arm 5, the best response was PR for four patients, SD for one patient and PD for six patients. On Arm 6, the best response was PR for 1 patient, SD for two patients, and PD for three patients (Table 5). Representative responders for Arms 3a, 4 , 5 and 6 are displayed in Supplementary Figures S1-S4. 
Table 2. Treatment arms and first cycle DLT

\begin{tabular}{|c|c|c|c|c|c|c|c|c|c|c|}
\hline $\begin{array}{l}\text { Study } \\
\text { number }\end{array}$ & $\begin{array}{l}\text { Age } \\
\text { at } \\
\text { entry }\end{array}$ & Gender & Cancer type & $\begin{array}{l}\text { Prior tx for mets } \\
\text { disease }\end{array}$ & $\begin{array}{l}\text { Prior } \\
\text { brain } \\
\text { mets }\end{array}$ & $\begin{array}{l}\text { KPS at } \\
\text { start } \\
(\%)\end{array}$ & $\begin{array}{c}\text { Time on } \\
\text { Tx } \\
\text { (months) }\end{array}$ & $\begin{array}{c}\text { Best } \\
\text { response }\end{array}$ & $\begin{array}{c}\text { Survival } \\
\text { status }\end{array}$ & $\begin{array}{c}\text { Overall } \\
\text { survival } \\
\text { (months) }\end{array}$ \\
\hline $1-0001$ & 31 & $\mathrm{~F}$ & SCC cervix & 2 lines $\mathrm{CT}, \mathrm{XRT}$ & No & 90 & 2.1 & PD & Deceased & 10.4 \\
\hline $1-0003$ & 60 & $\mathrm{~F}$ & $\mathrm{ER} / \mathrm{PR}+\mathrm{BC}$ & XRT & No & 100 & 2.1 & PD & Deceased & 14.1 \\
\hline $1-0004$ & 46 & $\mathrm{~F}$ & $\mathrm{ER} / \mathrm{PR}+\mathrm{BC}$ & 1 line $\mathrm{CT}, 1$ line HT & No & 80 & 2 & PD & Deceased & 8.6 \\
\hline $2-0001$ & 61 & M & $\begin{array}{c}\text { NSCLC-adenocarcinoma } \\
\text { EGFR, KRAS, ALK, ROS1 } \\
\text { wt }\end{array}$ & 2 lines $C T, X R T$ & No & 80 & 4 & SD & Deceased & 11.6 \\
\hline 3-0001 & 63 & $M$ & PDAC & $s x$ & No & 80 & 9.1 & SD & Deceased & 10.3 \\
\hline 3-0007 & 62 & $M$ & PDAC & $s x$ & No & 90 & 10.8 & PR & Deceased & 15 \\
\hline $3-0008$ & 63 & $\mathrm{~F}$ & PDAC & None & No & 100 & 4.4 & SD & Alive & 11.3 \\
\hline $3-0009$ & 57 & $\mathrm{~F}$ & PDAC & None & No & 80 & 4.9 & SD & Deceased & 6.7 \\
\hline $3-0010$ & 61 & $\mathrm{~F}$ & PDAC & None & No & 80 & 4.9 & SD & Deceased & 7.1 \\
\hline 3-0011 & 52 & $\mathrm{~F}$ & PDAC & 1 line $C T, X R T$ & No & 80 & 2 & PD & Deceased & 2.9 \\
\hline 3-0013 & 46 & $\mathrm{~F}$ & PDAC & 1 line CT & No & 80 & 2.1 & PD & Deceased & 4.1 \\
\hline $4-0001$ & 64 & $\mathrm{~F}$ & $\begin{array}{c}\text { NSCLC-adenocarcinoma } \\
\text { EGFR, KRAS, ALK, ROS1 } \\
\text { wt }\end{array}$ & $\begin{array}{c}1 \text { line } \mathrm{CT}, 1 \text { line another PD- } \\
1 \text { inhibitor }\end{array}$ & No & 80 & 3 & SD & Deceased & 5.7 \\
\hline $4-0002$ & 56 & $\mathrm{~F}$ & TNBC & 1 line CT & No & 80 & 1.6 & PD & Deceased & 12.8 \\
\hline $4-0008$ & 55 & $\mathrm{~F}$ & $\mathrm{ER} / \mathrm{PR}+\mathrm{BC}$ & $\begin{array}{c}1 \text { line } \mathrm{CT}, 2 \text { lines } \mathrm{HT}, 1 \text { line } \\
\mathrm{TT}, \mathrm{SX}\end{array}$ & No & 80 & 4.9 & SD & Deceased & 14.9 \\
\hline $4-0009$ & 27 & $\mathrm{~F}$ & Synovial sarcoma & 1 line $\mathrm{CT}, \mathrm{XRT}$ & No & 90 & 2.6 & PD & Alive & 13.3 \\
\hline $4-0010$ & 58 & $\mathrm{~F}$ & $\mathrm{ER} / \mathrm{PR}+\mathrm{BC}$ & $\begin{array}{c}1 \text { line } \mathrm{CT}, 3 \text { lines } \mathrm{HT}, 1 \text { line } \\
\mathrm{TT}, \mathrm{XRT}\end{array}$ & No & 90 & 2.1 & PD & Deceased & 5.1 \\
\hline $4-0011$ & 46 & $\mathrm{~F}$ & $\mathrm{ER} / \mathrm{PR}+\mathrm{BC}$ & 3 lines $C T, 2$ lines $H T$ & No & 90 & 3 & PD & Alive & 8.4 \\
\hline $4-0012$ & 61 & $\mathrm{~F}$ & $\mathrm{ER} / \mathrm{PR}+\mathrm{BC}$ & 2 lines $C T$ & No & 90 & 6.5 & SD & Alive & 7.9 \\
\hline $5-0001$ & 57 & M & SCLC & 1 line $C T, X R T$ & No & 90 & 10.6 & PR & Deceased & 23.3 \\
\hline $5-0002$ & 44 & $\mathrm{~F}$ & $\mathrm{SCLC}$ & 1 line CT & No & 90 & 10.5 & PR & Alive & 23.4 \\
\hline $5-0003$ & 33 & $\mathrm{~F}$ & $\begin{array}{c}\text { NSCLC-adenocarcinoma } \\
\text { EGFR }+\end{array}$ & $\begin{array}{l}1 \text { line CT, } 2 \text { lines TT, } 1 \text { line } \\
\text { another PD-1 inhibitor, XRT } \\
\end{array}$ & Yes & 80 & 2.1 & PD & Deceased & 3.7 \\
\hline $5-0004$ & 48 & $\mathrm{~F}$ & $\begin{array}{l}\text { NSCLC-adenocarcinoma } \\
\text { KRAS + }\end{array}$ & 2 lines $C T$ & No & 80 & 2 & PD & Deceased & 2.4 \\
\hline $5-0005$ & 45 & M & $\begin{array}{l}\text { NSCLC-adenocarcinoma } \\
\text { KRAS }+\end{array}$ & 2 lines $C T$ & No & 80 & 0.2 & PD & Deceased & 1.6 \\
\hline $5-0006$ & 60 & M & $\begin{array}{c}\text { NSCLC-adenocarcinoma } \\
\text { EGFR }+\end{array}$ & 4 lines $C T, 2$ lines TT, XRT & Yes & 80 & 4.4 & SD & Deceased & 6.5 \\
\hline $5-0007$ & 59 & M & $\begin{array}{l}\text { NSCLC-adenocarcinoma } \\
\text { KRAS }+\end{array}$ & 2 lines $C T, X R T$ & Yes & 90 & 11.8 & $P R$ & Alive & 17.5 \\
\hline $5-0008$ & 51 & $\mathrm{~F}$ & $\mathrm{SCLC}$ & 1 line $C T, X R T$ & No & 90 & 1.7 & PD & Deceased & 2.9 \\
\hline $5-0009$ & 61 & $\mathrm{~F}$ & $\begin{array}{c}\text { NSCLC-adenocarcinoma } \\
\text { EGFR, KRAS, ALK, } \\
\text { ROS1 wt }\end{array}$ & 1 line CT & No & 80 & 0.7 & $\mathrm{NE}$ & Deceased & 6.1 \\
\hline
\end{tabular}


Table 2. (Continued)

\begin{tabular}{|c|c|c|c|c|c|c|c|c|c|c|}
\hline $\begin{array}{l}\text { Study } \\
\text { number }\end{array}$ & $\begin{array}{c}\text { Age } \\
\text { at } \\
\text { entry }\end{array}$ & Gender & Cancer type & $\begin{array}{c}\text { Prior tx for mets } \\
\text { disease }\end{array}$ & $\begin{array}{l}\text { Prior } \\
\text { brain } \\
\text { mets }\end{array}$ & $\begin{array}{c}\text { KPS at } \\
\text { start } \\
(\%)\end{array}$ & $\begin{array}{c}\text { Time on } \\
\text { Tx } \\
\text { (months) }\end{array}$ & $\begin{array}{c}\text { Best } \\
\text { response }\end{array}$ & $\begin{array}{c}\text { Survival } \\
\text { status }\end{array}$ & $\begin{array}{c}\text { Overall } \\
\text { survival } \\
\text { (months) }\end{array}$ \\
\hline $5-0010$ & 60 & M & SCLC & 1 line $C T, X R T$ & No & 90 & 13.7 & PR & Alive & 13.8 \\
\hline $5-0011$ & 49 & M & Colorectal cancer-MSI + & 1 line CT & No & 80 & 2.7 & PD & Deceased & 9.5 \\
\hline $5-0012$ & 41 & M & $\begin{array}{c}\text { Esophageal-HER2 } \\
\text { negative }\end{array}$ & 1 line CT & No & 80 & 15.4 & PD & Deceased & 15.4 \\
\hline 6-0003 & 52 & M & $\begin{array}{c}\text { Malignant fibrious } \\
\text { histiocytoma (sarcoma) }\end{array}$ & $s x$ & No & 80 & 2.6 & PD & Deceased & 13.1 \\
\hline 6-0004 & 59 & $\mathrm{~F}$ & OC & 4 lines $C T$ & No & 90 & 15.5 & SD & Alive & 22.4 \\
\hline 6-0005 & 32 & $\mathrm{~F}$ & Clear cell sarcoma & sX & No & 90 & 4.7 & PD & Deceased & 6.9 \\
\hline 6-0006 & 56 & $\mathrm{~F}$ & OC & 1 line CT & No & 90 & 10.5 & PR & Alive & 17.3 \\
\hline
\end{tabular}

Table 3. Treatment arms and first cycle DLT

\begin{tabular}{|c|c|c|c|}
\hline $\begin{array}{l}\text { Treatment } \\
\text { arm }\end{array}$ & $\begin{array}{l}\text { Number of } \\
\text { treated patients }\end{array}$ & $\begin{array}{l}\text { No of patients } \\
\text { with cycle } 1 \mathrm{DLT}\end{array}$ & DLT \\
\hline 1 & 6 & 1 & Grade 4 neutropenia leading to $\geqslant 25 \%$ missed planned dose of treatment \\
\hline 2 & 1 & 0 & None \\
\hline 3 & 11 & 2 & $\begin{array}{c}\text { Two with grade } 3 \text { thrombocytopenia leading to } \geqslant 25 \% \text { missed planned dose of treatment (both } \\
\text { patients were previously treated with systemic chemotherapy for advanced disease) }\end{array}$ \\
\hline \multirow[t]{2}{*}{4} & 12 & 3 & $\begin{array}{c}\text { Dose level 1: Grade } 3 \text { and grade } 4 \text { neutropenia, respectively, leading to } \geqslant 25 \% \text { missed planned } \\
\text { dose of treatment }\end{array}$ \\
\hline & & & Dose level -1 : Grade 3 thrombocytopenia leading to $\geqslant 25 \%$ missed planned dose of treatment \\
\hline \multirow[t]{2}{*}{5} & 12 & 3 & Dose level 1: Grade 3 fatigue and grade 3 nausea, vomiting and diarrhoea, respectively. \\
\hline & & & Dose level -1: Grade 3 rash and papilloedema \\
\hline 6 & 7 & 0 & None \\
\hline
\end{tabular}

\section{DISCUSSION}

In 2016, nearly 600000 individuals diagnosed with cancer will die from their disease (Cancer Facts \& Figures 2016 | American Cancer Society). While some may have long-term disease-free intervals, for most individuals who are diagnosed with metastatic disease, the survival rate is less than 5 years. For primary cancers of the lung, connective tissue or pancreas, few individuals will live 2 years with metastatic disease. Patients with metastatic disease are usually treated with systemic chemotherapy, with the intent of prolonging survival and palliate symptoms (e.g., pain, weight loss and decreased performance status). For the most common advanced stage cancer, there are consensus guideline first- and/or second-line systemic treatment recommendations. Year after year, randomised trials are designed and launched to try and improve on median overall survival outcomes. In oncology, the success rate from phase I to FDA approval is a dismal 11\% (Hay, 2011). Even with the successful phase III clinical trials, the improvement in overall survival is modest, increasing the median by weeks to several months. For common non-haematologic cancers (and many rare cancers), there are no design strategies that are primarily seeking to attain complete (and hopefully durable) responses.
There have been promising results with checkpoint inhibitors across multiple tumours, including in melanoma, renal cell carcinoma and NSCLC (Topalian et al, 2012; Robert et al, 2014). There is now accumulating data on the presence of PD-L1 expression across a number of tumour types, including SCLC, PDAC and sarcoma (Bigelow et al, 2013; Kim et al, 2013; Yu et al, 2017). While PD-L1 and/or mutational tumour burden appear to be useful for identifying those most likely to benefit from singleagent checkpoint inhibition, when combination therapy is considered this biomarker does not appear to have a definitive role (Topalian et al, 2012; Wolchok et al, 2013; Le et al, 2015). Additionally, the functional state of the host immune system and/ or its interaction with microbiota can have an impact on the therapeutic efficacy of systemic treatment (Sivan et al, 2015; Vetizou et al, 2015).

The present study is one of the first reported multi-arm systemic chemotherapy in combination with PD-1 inhibitors across diverse advanced solid tumours. Several systemic chemotherapy agents have been implicated in having immunotherapeutic-enhancing properties. For the agents evaluated in this study, we briefly outline the reported effects of gemcitabine, docetaxel, paclitaxel, vinorelbine, irinotecan and doxorubicin (Galluzzi et al, 2012; Duffy and Greten, 2014). Gemcitabine can increase class I HLA expression, 
Table 4. Treatment emergent adverse events ( $>20 \%$ all grades, $>10 \%$ for grades $3-4$ )

\begin{tabular}{|c|c|c|c|c|c|c|c|c|c|c|c|c|c|c|c|}
\hline \multirow[b]{2}{*}{ Preferred term } & \multirow[b]{2}{*}{ CTC grade } & \multicolumn{2}{|c|}{$\begin{array}{l}\text { Arm } 1 \\
(N=6)\end{array}$} & \multicolumn{2}{|c|}{$\begin{array}{l}\text { Arm 2 } \\
(N=1)\end{array}$} & \multicolumn{2}{|c|}{$\begin{array}{c}\text { Arm 3a } \\
(N=9)\end{array}$} & \multicolumn{2}{|c|}{$\begin{array}{c}\text { Arm 3b } \\
(N=2)\end{array}$} & \multicolumn{2}{|c|}{$\begin{array}{c}\text { Arm } 4 \\
(N=12)\end{array}$} & \multicolumn{2}{|c|}{$\begin{array}{c}\text { Arm 5 } \\
(n=12)\end{array}$} & \multicolumn{2}{|c|}{$\begin{array}{l}\text { Arm } 6 \\
(n=7)\end{array}$} \\
\hline & & $n$ & $\%$ & $n$ & $\%$ & $n$ & $\%$ & $n$ & $\%$ & $n$ & $\%$ & $n$ & $\%$ & $n$ & $\%$ \\
\hline \multirow[t]{2}{*}{ Any term } & $1-4$ & 6 & 100 & 1 & 100 & 9 & 100 & 2 & 200 & 12 & 100 & 12 & 100 & 7 & 100 \\
\hline & $3-4$ & 5 & 83.3 & 1 & 100 & 6 & 66.7 & 1 & 50 & 8 & 75 & 3 & 25 & 4 & 57.1 \\
\hline \multirow[t]{2}{*}{ Thrombocytopenia } & $1-4$ & 2 & 33.3 & 1 & 100 & 4 & 44.4 & 1 & 50 & 7 & 58.3 & & & & \\
\hline & $3-4$ & & & & & 3 & 33.3 & & & & & & & & \\
\hline \multirow[t]{2}{*}{ Neutropenia } & $1-4$ & 3 & 50 & 1 & 100 & 3 & 33.3 & & & 8 & 75 & 3 & 25 & & \\
\hline & $3-4$ & 3 & 50 & 1 & 100 & 2 & 22.2 & & & 4 & 33.3 & & & & \\
\hline \multirow[t]{2}{*}{ Anaemia NOS } & $1-4$ & 2 & 33.3 & 1 & 100 & 8 & 88.9 & 1 & 50 & 8 & 75 & & & 2 & 28.6 \\
\hline & $3-4$ & & & & & & & & & 2 & 16.7 & & & & \\
\hline \multirow[t]{2}{*}{ AST elevation } & $1-4$ & 5 & 83.3 & & & 4 & 44.4 & & & 7 & 58.3 & & & & \\
\hline & $3-4$ & 2 & 33.3 & & & 1 & 11.1 & & & 2 & 16.7 & & & & \\
\hline \multirow[t]{2}{*}{ ALT elevation } & $1-4$ & 4 & 66.7 & & & 6 & 66.7 & & & 7 & 58.3 & & & & \\
\hline & $3-4$ & 2 & 33.3 & & & 1 & 11.1 & & & & & & & & \\
\hline \multirow[t]{2}{*}{ Fatigue } & $1-4$ & 2 & 33.3 & 1 & 100 & 5 & 55.5 & & & 4 & 33.3 & 5 & 41.7 & 2 & 28.6 \\
\hline & $3-4$ & 1 & 16.7 & & & & & & & & & & & & \\
\hline Hyponatraemia & $1-4$ & & & 1 & 100 & 3 & 33.3 & & & & & & & & \\
\hline & $3-4$ & & & & & 2 & 22.2 & & & & & & & & \\
\hline White blood cell count decreased & $1-4$ & 4 & 66.7 & 1 & 100 & & & & & 9 & 75 & & & & \\
\hline & $3-4$ & 3 & 50 & 1 & 100 & & & & & 3 & 25 & & & & \\
\hline Thrombolic event & $1-4$ & & & & & 3 & 33.3 & & & & & & & & \\
\hline & $3-4$ & & & & & 1 & 11.1 & & & & & & & & \\
\hline ALK increased & $1-4$ & & & & & & & 2 & 100 & 3 & 25 & & & & \\
\hline & $3-4$ & & & & & & & 1 & 50 & & & & & & \\
\hline Diarrhoea & $1-4$ & & & & & 3 & 33.3 & & & & & 9 & 75 & 3 & 42.9 \\
\hline & $3-4$ & & & & & & & & & & & & & 1 & 14.3 \\
\hline Pruritus & $1-4$ & & & & & 2 & 22.2 & & & 3 & 25 & & & 2 & 28.6 \\
\hline & $3-4$ & & & & & & & & & & & & & 1 & 14.3 \\
\hline Palmar-plantar erythrodysesthesia & $1-4$ & & & & & & & & & & & & & 2 & 28.6 \\
\hline & $3-4$ & & & & & & & & & & & & & 1 & 14.3 \\
\hline Peripheral sensory neuropathy & $1-4$ & & & & & 4 & 44.4 & & & & & & & & \\
\hline & $3-4$ & & & & & 1 & 11.1 & & & & & & & & \\
\hline Nausea & $1-2$ & & & & & 2 & 22.2 & 1 & 50 & 5 & 41.7 & 8 & 75 & 2 & 28.6 \\
\hline Vomiting & $1-2$ & 3 & 50 & & & 3 & 33.3 & 1 & 50 & 3 & 25 & 4 & 33.3 & 2 & 28.6 \\
\hline Rash NOS & $1-2$ & 2 & 33.3 & 1 & 100 & 4 & 44.4 & 1 & 50 & & & 3 & 25 & 5 & 71.4 \\
\hline Constipation & $1-2$ & & & & & 1 & 11.1 & 1 & 50 & 4 & 33.3 & & & & \\
\hline Weight loss & $1-2$ & & & 1 & 100 & 2 & 22.2 & & & & & & & & \\
\hline Dysgeusia & $1-2$ & & & 1 & 100 & 2 & 22.2 & & & & & & & & \\
\hline Oedema in limbs & $1-2$ & & & 1 & 100 & 2 & 22.2 & & & & & & & & \\
\hline Tracheal hemorrhage & $1-2$ & & & 1 & 100 & & & & & & & & & & \\
\hline Haematoma & $1-2$ & & & 1 & 100 & & & & & & & & & & \\
\hline Pain in extremities & $1-2$ & & & 1 & 100 & 3 & 33.3 & 1 & 50 & 4 & 33.3 & 4 & 33.3 & & \\
\hline Hypertension & $1-2$ & & & 1 & 100 & & & & & & & & & & \\
\hline Pleural effusion & $1-2$ & & & 1 & 100 & & & & & & & & & & \\
\hline Mucositis oral & $1-2$ & & & & & 3 & 33.3 & & & & & & & 3 & 42.9 \\
\hline Hypoalbuminaemia & $1-2$ & & & & & 3 & 33.3 & & & 4 & 33.3 & & & & \\
\hline Dehydration & $1-2$ & & & & & 3 & 33.3 & & & & & & & & \\
\hline Fever & $1-2$ & & & & & 5 & 55.5 & & & & & & & & \\
\hline Insomnia & $1-2$ & & & & & 4 & 44.4 & & & & & & & & \\
\hline Cough & $1-2$ & & & & & & & 1 & 50 & & & & & & \\
\hline Epistaxis & $1-2$ & & & & & 2 & 22.2 & & & & & & & & \\
\hline
\end{tabular}




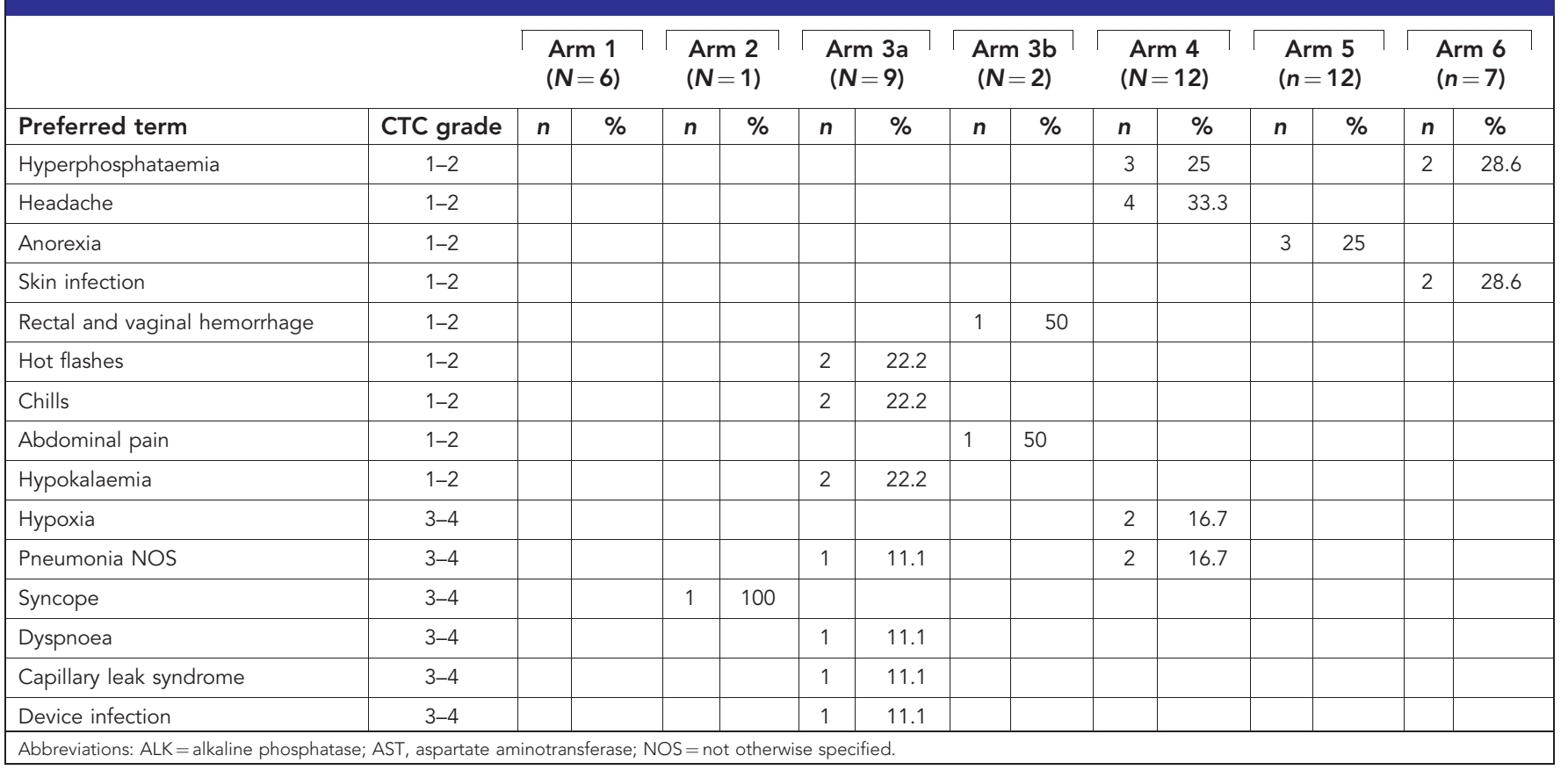

Table 5. Best tumour response

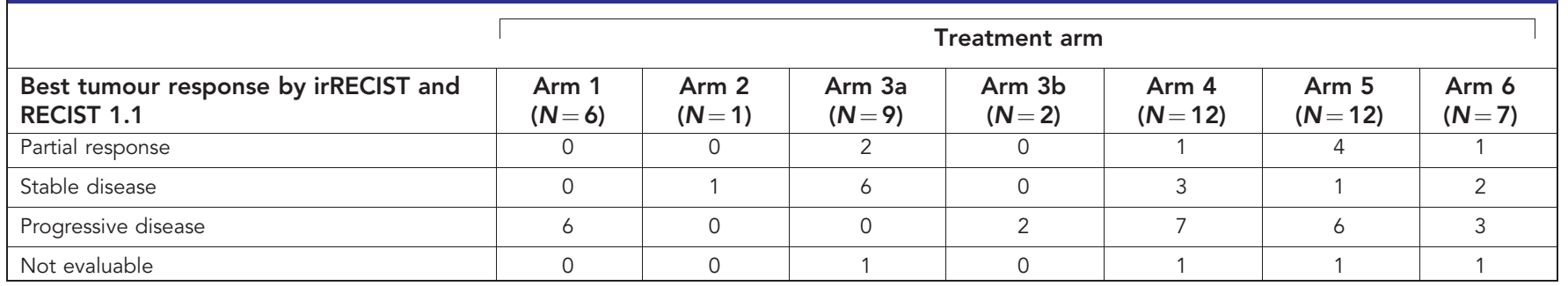

enhance tumour antigen cross-presentation and selectively kill MDSCs. Docetaxel can decrease MDSCs. Paclitaxel can stimulate antigen-presenting dendritic cells and increase tumour cell permeability to granzyme $\mathrm{B}$. Vinorelbine can facilitate the bystander death of immune cells. Irinotecan can decrease MDSC and Tregs. Doxorubicin can induce immunogenic cell death, increase tumour cell permeability to granzyme B and stimulate antigen presentation dendritic cells.

Overall, 50 patients with advanced/metastatic solid tumours were enrolled and 47 were evaluable for the primary endpoint. Each completed treatment arm has a RP2D. Arm 3b is unlikely to complete accrual for RP2D. Main toxicities observed were transaminitis, cytopenias, rash, diarrhoea, fatigue, nausea and vomiting. There do not appear to be a signal for increased immune-related AEs, particularly once dexamethasone premedication was administered on the days of systemic chemotherapy infusion. There were multiple responses observed and a few appear to be supra-normal and may be a signal of potential synergy. The phase II portions of the arms with a RP2D are ongoing and subsequent future reporting of those results are planned.

There are ongoing studies involving a variety of immunotherapy plus targeted or chemotherapy agents now across a number of different cancer types and it remains to be seen which of these combinations will be true game changers and deliver long lasting responses with manageable or minimal toxicity. In conclusion, this study was successful in identifying the RP2D of multiple systemic chemotherapies in combination with $\mathrm{P}$ and in characterising the safety profile of these combinations on a 21-day treatment cycle.

\section{ACKNOWLEDGEMENTS}

We thank the cancer patients who participated and all clinical staff who assisted. This study was sponsored by Western Regional Medical Center, Inc.

\section{CONFLICT OF INTEREST}

GJW: Consultant for Blend Therapeutics, Pharmatech, Viomics and Paradigm; Speakers' Bureau: Medscape, Merck, Novartis; Travel/accommodations: NantWorks. JN: Consultant for Astrazeneca and Eisai; JHF: Genentech speaker's bureau; and VK: Consultant for Axcess Oncology. The remaining authors declare no conflict of interest.

\section{AUTHOR CONTRIBUTIONS}

Conception and design: VK and GJW; acquisition of data: all authors; analysis and interpretation of data: VK and GJW; writing, 
review and/or revision of the manuscript: all authors; administrative, technical or material support (e.g., reporting or organising data, constructing databases): LB, JC, JW, KG and GJW; study supervision: VK and GJW.

\section{REFERENCES}

Bigelow E, Bever KM, Xu H, Yager A, Wu A, Taube J, Chen L, Jaffee EM, Anders RA, Zheng L (2013) Immunohistochemical staining of B7-H1 (PD-L1) on paraffin-embedded slides of pancreatic adenocarcinoma tissue. J Vis Exp 71: 4059.

Cancer Facts \& Figures 2016 | American Cancer Society. http:// www.cancer.org/research/cancerfactsstatistics/cancerfactsfigures2016/ (accessed: 28 December 2016).

Duffy AG, Greten TF (2014) Immunological off-target effects of standard treatments in gastrointestinal cancers. Ann Oncol 25: 24-32.

Eisenhauer EA, Therasse P, Bogaerts J, Schwartz LH, Sargent D, Ford R, Dancey J, Arbuck S, Gwyther S, Mooney M, Rubinstein L, Shankar L, Dodd L, Kaplan R, Lacombe D, Verweij J (2009) New response evaluation criteria in solid tumours: revised RECIST guideline (version 1.1). Eur J Cancer 45: 228-247.

Galluzzi L, Senovilla L, Zitvogel L, Kroemer G (2012) The secret ally: immunostimulation by anticancer drugs. Nat Rev Drug Discov 11: 215-233.

Hay M (2011) BIO/BioMedTracker Clinical Trial Success Rates Study.

Herzberg B, Campo MJ, Gainor JF (2016) Immune checkpoint inhibitors in non-small cell lung cancer. Oncologist 22(1): 81-88.

Kim JR, Moon YJ, Kwon KS, Bae JS, Wagle S, Kim KM, Park HS, Lee H, Moon WS, Chung MJ, Kang MJ, Jang KY (2013) Tumor infiltrating PD1positive lymphocytes and the expression of PD-L1 predict poor prognosis of soft tissue sarcomas. PLoS One 8: e82870.

Langer CJ, Gadgeel SM, Borghaei H, Papadimitrakopoulou VA, Patnaik A, Powell SF, Gentzler RD, Martins RG, Stevenson JP, Jalal SI, Panwalkar A, Yang JC-H, Gubens M, Sequist L V, Awad MM, Fiore J, Ge Y, Raftopoulos H, Gandhi L. KEYNOTE-021 investigators (2016) Carboplatin and pemetrexed with or without pembrolizumab for advanced, non-squamous non-small-cell lung cancer: a randomised, phase 2 cohort of the open-label KEYNOTE-021 study. Lancet Oncol 17: 1497-1508.

Le DT, Uram JN, Wang H, Bartlett BR, Kemberling H, Eyring AD, Skora AD, Luber BS, Azad NS, Laheru D, Biedrzycki B, Donehower RC, Zaheer A, Fisher GA, Crocenzi TS, Lee JJ, Duffy SM, Goldberg RM, de la Chapelle A, Koshiji M, Bhaijee F, Huebner T, Hruban RH, Wood LD, Cuka N, Pardoll DM, Papadopoulos N, Kinzler KW, Zhou S, Cornish TC, Taube JM, Anders RA, Eshleman JR, Vogelstein B, Diaz LA (2015) PD-1 blockade in tumors with mismatch-repair deficiency. N Engl J Med 372: 2509-2520.

Le Tourneau C, Lee JJ, Siu LL (2009) Dose escalation methods in phase I cancer clinical trials. J Natl Cancer Inst 101: 708-720.

Nishino M, Giobbie-Hurder A, Gargano M, Suda M, Ramaiya NH, Hodi FS (2013) Developing a common language for tumor response to immunotherapy: immune-related response criteria using unidimensional measurements. Clin Cancer Res 19: 3936-3943.

Rizvi NA, Hellmann MD, Brahmer JR, Juergens RA, Borghaei H, Gettinger S, Chow LQ, Gerber DE, Laurie SA, Goldman JW, Shepherd FA, Chen AC, Shen Y, Nathan FE, Harbison CT, Antonia S (2016) Nivolumab in combination with platinum-based doublet chemotherapy for first-line treatment of advanced non-small-cell lung cancer. J Clin Oncol 34: 2969-2979.

Robert C, Ribas A, Wolchok JD, Hodi FS, Hamid O, Kefford R, Weber JS, Joshua AM, Hwu W-J, Gangadhar TC, Patnaik A, Dronca R, Zarour H, Joseph RW, Boasberg P, Chmielowski B, Mateus C, Postow MA, Gergich K, Elassaiss-Schaap J, Li XN, Iannone R, Ebbinghaus SW, Kang SP, Daud A (2014) Anti-programmed-death-receptor-1 treatment with pembrolizumab in ipilimumab-refractory advanced melanoma: a randomised dose-comparison cohort of a phase 1 trial. Lancet 384(9948): $1109-1117$.

Sivan A, Corrales L, Hubert N, Williams JB, Aquino-Michaels K, Earley ZM, Benyamin FW, Man Lei Y, Jabri B, Alegre M-L, Chang EB, Gajewski TF (2015) Commensal Bifidobacterium promotes antitumor immunity and facilitates anti-PD-L1 efficacy. Science 350: 1084-1089.

Topalian SL, Hodi FS, Brahmer JR, Gettinger SN, Smith DC, McDermott DF, Powderly JD, Carvajal RD, Sosman JA, Atkins MB, Leming PD, Spigel DR, Antonia SJ, Horn L, Drake CG, Pardoll DM, Chen L, Sharfman WH, Anders RA, Taube JM, McMiller TL, Xu H, Korman AJ, Jure-Kunkel M, Agrawal S, McDonald D, Kollia GD, Gupta A, Wigginton JM, Sznol M (2012) Safety, activity, and immune correlates of anti-PD-1 antibody in cancer. N Engl J Med 366: 2443-2454.

Vetizou M, Pitt JM, Daillere R, Lepage P, Waldschmitt N, Flament C, Rusakiewicz S, Routy B, Roberti MP, Duong CPM, Poirier-Colame V, Roux A, Becharef S, Formenti S, Golden E, Cording S, Eberl G, Schlitzer A, Ginhoux F, Mani S, Yamazaki T, Jacquelot N, Enot DP, Berard M, Nigou J, Opolon P, Eggermont A, Woerther P-L, Chachaty E, Chaput N, Robert C, Mateus C, Kroemer G, Raoult D, Boneca IG, Carbonnel F, Chamaillard M, Zitvogel L (2015) Anticancer immunotherapy by CTLA-4 blockade relies on the gut microbiota. Science 350: 1079-1084.

Wolchok JD, Kluger H, Callahan MK, Postow MA, Rizvi NA, Lesokhin AM, Segal NH, Ariyan CE, Gordon R-A, Reed K, Burke MM, Caldwell A, Kronenberg SA, Agunwamba BU, Zhang X, Lowy I, Inzunza HD, Feely W, Horak CE, Hong Q, Korman AJ, Wigginton JM, Gupta A, Sznol M (2013) Nivolumab plus ipilimumab in advanced melanoma. N Engl J Med 369: 122-133.

Yu H, Batenchuk C, Badzio A, Boyle TA, Czapiewski P, Chan DC, Lu X, Gao D, Ellison K, Kowalewski AA, Rivard CJ, Dziadziuszko R, Zhou C, Hussein M, Richards D, Wilks S, Monte M, Edenfield W, Goldschmidt J, Page R, Ulrich B, Waterhouse D, Close S, Jassem J, Kulig K, Hirsch FR (2017) PD-L1 expression by two complementary diagnostic assays and mRNA in situ hybridization in small cell lung cancer. J Thorac Oncol 12: 110-120.

Zitvogel L, Galluzzi L, Smyth MJ, Kroemer G (2013) Mechanism of action of conventional and targeted anticancer therapies: reinstating immunosurveillance. Immunity 39: 74-88.

Zitvogel L, Kepp O, Kroemer G (2011) Immune parameters affecting the efficacy of chemotherapeutic regimens. Nat Rev Clin Oncol 8: 151-160.

This work is published under the standard license to publish agreement. After 12 months the work will become freely available and the license terms will switch to a Creative Commons AttributionNonCommercial-Share Alike 4.0 Unported License.

Supplementary Information accompanies this paper on British Journal of Cancer website (http://www.nature.com/bjc) 